\title{
Efficacy and Safety of Retrobulbar Blockade of 0.5\% Ropivacaine During Eyeball Enucleation Surgery in Children with Retinoblastoma
}

ISSN: 2576-9200

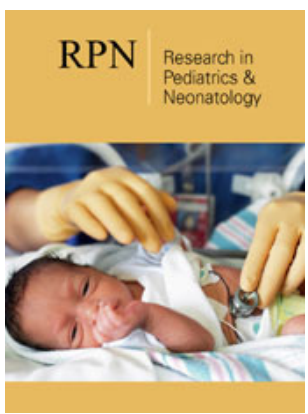

*Corresponding author: Ushakova $\mathrm{TL}$, Blokhin National Medical Research Center of Oncology, Russian Medical Academy of Postgraduate Education, Moscow, Russia

Submission: 眥 February 20, 2020

Published: 㭗 March 12, 2020

Volume 4 - Issue 3

How to cite this article: Belousova $\mathrm{EI}$ Matinyan NV, Ushakova TL, Polyakov VG. Efficacy and Safety of Retrobulbar Blockade of $0.5 \%$ Ropivacaine During Eyeball Enucleation Surgery in Children with Retinoblastoma. Res Pediatr Neonatol. 4(3).RPN.000587.2020. DOI: $10.31031 /$ RPN.2020.04.000587

Copyright $($ C Ushakova TL. This article is distributed under the terms of the Creative Commons Attribution 4.0 International License, which permits unrestricted use and redistribution provided that the original author and source are credited.

\author{
Belousova EI ${ }^{1}$, Matinyan NV ${ }^{1,2}$, Ushakova $\mathrm{TL}^{1,3 *}$ and Polyakov VG ${ }^{1,3}$ \\ ${ }^{1}$ Blokhin National Medical Research Center of Oncology, Russia \\ ${ }^{2}$ Pirogov Russian National Research Medical University, Russia \\ ${ }^{3}$ Russian Medical Academy of Postgraduate Education, Russia
}

\section{Introduction}

Retinoblastoma is the most common intraocular malignant tumor in children. The annual incidence is 10-14 people under the age of 5 years [1]. Eye removal is performed in the presence of a massive lesion of the retina and vitreous body; secondary glaucoma; tumor invasion into the anterior chamber; hemophthalmia and with the failure of organ-preserving treatment [24]. Enucleation in children is performed under general anesthesia $(\mathrm{OA})$ and is accompanied by a high incidence of oculocardial reflex (OCR), as well as postoperative nausea, vomiting (PONV) and agitation [5]. Regional anesthesia can not only provide effective analgesia, but also protect against OCR and PONV. In pediatric vitreoretinal surgery, parabulbar blockade is predominantly used, the analgesic efficacy of which is significantly lower than with retrobulbar blockade, which is a limitation for its use in eyeball removal operations. To date, no studies have been conducted on the effectiveness and safety of retrobulbar blockade for the prevention of OCR and PONV during the operation of enucleation of the eyeball in children with retinoblastoma.

\section{Propose}

The aim of this study was to determine the effectiveness and safety of retrobulbar blockade with ropivacaine $0.5 \%$ for the prevention of OCR intra and postoperative pain, as well as postoperative nausea and vomiting during eyeball enucleation surgery.

\section{Method}

A prospective randomized clinical trial. Eighty patients who were scheduled to undergo enucleation surgery for a retinoblastoma tumor disease were randomized to the RB group (retrobulbar blockade with ropivacaine $0.5 \%$ against the background of general anesthesia $\mathrm{N}=40$ ) and the control group GA (general anesthesia $\mathrm{N}=40$ ). There were no significant differences in weight and gender between the two groups. The demographic and biometric data of the patients, as well as the duration of anesthesia and the average age among the groups were comparable. For all cases, a standard operation was performed. Between the two groups, a comparison and assessment of the prevalence and severity of OCR was carried out, which was defined as a rapid decrease in heart rate by $20 \%$ from the baseline values or the presence of arrhythmia during manipulations with the eyeball. The analysis of the intensity of postoperative pain using a visual analogue scale (VAS), the frequency of postoperative vomiting.

\section{Result}

Table 1 shows some hemodynamic parameters in the study groups during 4 observation periods, the greater stability of indicators in patients from the RB group is noteworthy. There were no complications in the RB group associated with the methodology. None of the patients had OCR or other complications during retrobulbar blockade. OCR in the RB group was observed in 2 patients (5\%), the average decrease in the rhythm from the baseline values for traction of the eyeball or muscles was $6.1 \pm 2.9$ beats per minute, which is significantly 
lower than in the GA group, where OCR was noted in all patients an average of $38.7 \pm 6.9$ beats. per minute $(\mathrm{P}<0.005)$. In $5(12.5 \%)$ patients from the GA group, arrhythmia was recorded. Atropine $(0.005 \mathrm{mg} / \mathrm{kg})$ was required in only 8 patients in the GA group.

Table 1: Change in hemodynamic parameters in study groups during surgery (Me, 25\%; 75\%).

\begin{tabular}{|c|c|c|c|c|}
\hline \multirow{2}{*}{} & \multicolumn{4}{|c|}{ Indicator values } \\
\cline { 2 - 5 } & Group & 1 & 2 & 3 \\
\hline \multirow{2}{*}{$\begin{array}{c}\text { Adsist } \\
\text { (mmHg) }\end{array}$} & RB & $90(88 ; 94)$ & $82(78,8 ; 86)$ & $84(79 ; 85,5)^{*}$ \\
\hline \multirow{2}{*}{$\begin{array}{c}\text { ADmid. } \\
\text { (mm.Hg) }\end{array}$} & GA & $100(87 ; 111)$ & $88(78 ; 94)^{*}$ & $91(84 ; 96,3)$ \\
\hline \multirow{2}{*}{$\begin{array}{c}\text { Heart rate } \\
\text { (bpm) }\end{array}$} & GA & $61(51 ; 70,5)$ & $52(45 ; 60)$ & $52,5(45 ; 61,5)^{*}$ \\
\cline { 2 - 5 } & GB & $129(118 ; 138)$ & $108 ; 90)$ & $66(60 ; 73,5)$ \\
\hline
\end{tabular}

Postoperative awakening in the RB group was smooth in all patients, the average duration was $3.7 \pm 0.35$ minutes, and in the $\mathrm{OA}$ group $22 \pm 8.3$ minutes. After tracheal extubation, laryngospasm developed in 7 (17.5\%) patients in the GA group. Estimates of postoperative pain were significantly lower in the RB group than in the control group (average score VAS 1.8 versus 3.760 minutes after surgery, $\mathrm{P}<0.001$ ). The average dose of fentanyl in the $\mathrm{RB}$ group was $4.7 \pm 0.7 \mu \mathrm{g} / \mathrm{kg}$, which is significantly lower than in the GA group $10.1 \pm 1.9 \mu \mathrm{g} / \mathrm{kg}(\mathrm{P}<0.005)$. PONV within 6 hours after surgery in the RB group was not observed, and in the control, group was observed in $45 \%$ of cases. Children in the RB group began to drink immediately after complete awakening, on average $1.2 \pm 0.9$ hours, after $2.7 \pm 0.5$ hours, enteral nutrition began. In the postoperative period, analgesia in the GA group was performed using a combination of opioid analgesics: promedol intramuscularly and NSAIDs in 21 (52.5\%) patients and tramadol with NSAIDs in $19(47.5 \%)$ patients. Despite the introduction of analgesics, 10 children needed sedation. In the GA group, only 20 (50\%) patients managed to start enteral nutrition after 6 hours.

\section{Conclusion}

Effective antiarrhythmic activity can provide retrobulbar blockade, blocking the afferent limb of the reflex arc. In our study, the frequency of OCR in the control group was higher than that reported in other studies, due to the high percentage of pediatric young patients, since in children, as a rule, the smaller, the higher the vagus nerve tone. Severe pain resulting from enucleation requires the use of strong analgesics, such as intravenous fentanyl, and in the postoperative period, tramadol or promedol. However, opioid analgesia increases the risk of PONV and that is why postoperative analgesia is crucial. Since retrobulbar blockade provides a more rapid development of the effect and requires a smaller amount of anesthetic than other regional methods, with the use of a $0.5 \%$ ropivacaine solution it can be used in children during enucleation operations. Retrobulbar blockade of ropivacaine $0.5 \%$ as a local anesthetic can significantly reduce the incidence of OCR and reduce the severity of bradycardia. This method can also reduce intra and postoperative pain in patients, as well as the incidence of postoperative nausea and vomiting.

\section{References}

1. Leahey A, Lanzkowsky P (2016) Manual of pediatric hematology and oncology $\left(5^{\text {th }} \mathrm{edn}\right)$, Elsevier, Netherlands, Europe.

2. Albert D, Miller J, Azar D, Blodi B (2008) Albert \& Jakobiec's principles and practice of ophthalmology ( $3^{\text {rd }} \mathrm{edn}$ ), Elsevier, Netherlands, Europe.

3. Nunery WR, Hetzler KJ. Enucleation In: Hornblass A, Hanig CJ (Eds.), Oculoplastic, orbital, and reconstructive surgery. Lippincott Williams and Wilkins, USA, PP. 1990-1200.

4. Watcha MF (2003) Management of postoperative vomiting in pediatric patients. Curr Opin Anaesthesiol 16(6): 575-583.

5. Gottfreothsdóttir MS, Gislason I, Stefanson E, Sigurjonsdothi S, Nielsen SC (1993) Effect of retro bulbar bupivacaine on postoperative pain and nausea in retinal detachment surgery. Acta Ophthalmologica 71(4): 544547.

For possible submissions Click below: 